\title{
Contraceptive Knowledge, Perceptions and Use among Adolescents in Selected Senior High Schools in the Central Region of Ghana
}

\author{
John Elvis Hagan (Corresponding author) \\ Department of Health, Physical Education and Recreation, \\ University of Cape Coast, Ghana \\ Tel: +233202508073Ｅ-mail: jaguwa2006@yahoo.co.uk
}

\author{
Christiana Buxton \\ Department of Science and Mathematics Education \\ (Health Sciences Education Programme), University of Cape Coast, Ghana \\ Tel: +233279668030Ｅ-mail: naabux@yahoo.com
}

Accepted: June 27, 2012 Published: August 29, 2012

Doi:10.5296/jsr.v3i2.2311 URL: http://dx.doi.org/10.5296/jsr.v3i2.2311

\begin{abstract}
Background: Teenage pregnancies, human immuno deficiency virus and other sexually transmitted diseases infection, are an important public health issue because they are associated with maternal, fetal, neonatal and other adverse outcomes. Adolescent girls who get pregnant are likely to drop out from school and adolescent parents are unlikely to have the social and economic means to raise children.
\end{abstract}

Objective: The study was conducted to assess contraceptive knowledge, perceptions and use among adolescents in selected Senior High Schools in the Central Region of Ghana.

Method: A cross-sectional study was carried out in the Cosmopolitan city of Cape Coast of the Central Region of Ghana. Three mixed, one female and one male senior high school were conveniently identified for the study. A self-administered questionnaire was given to 350 students in the schools out of which 300 were retrieved and used, representing a response rate of $85.7 \%$. The Statistical Package for the Social Sciences (SPSS) programme software (version 15.0) was used for data entry, and descriptive statistics tests were conducted for the items which were summarised by frequencies and percentages.

Results: Results showed that almost $21 \%$ of 244 students with knowledge of contraception are users, $82 \%$ of sexually active respondents were non-users while condom is the most common contraceptive method used. Also, $60 \%$ and $30 \%$ of respondents obtained knowledge about contraception from the media (TV/Radio) and peers (friends) respectively. However, almost $32 \%$ of the study participants thought contraceptives are for only adult married 
persons.

Conclusion: We believe that there is a need for aggressive advocacy and dissemination of information on Adolescent Reproductive Health (ARH) and family planning methods before initiation of sexual activity among the adolescent population in Ghana.

Key words: Ghana, Contraceptive Knowledge, Perceptions, Sexual Behaviour, Adolescent

\section{INTRODUCTION}

There is a growing interest in adolescent reproductive health. Teenage pregnancy is an important public health issue because they are associated with maternal, fetal, and neonatal adverse outcomes. Teenage girls who get pregnant are likely to drop out from school and teenage parents are unlikely to have the social and economic means to raise children (Whitaker \& Gilliam, 2008). Further, unintended pregnancy poses a major challenge to the reproductive health of young adults in developing countries. With decreasing age of menarche and onset of sexual activity, young people are exposed early to unplanned and unprotected sexual intercourse leading to unwanted pregnancies and invariably abortions especially very common in many Sub-Saharan African countries where persistent high rates of unmet need for family planning and low rates of contraceptive use are reported (Okonofua, 1995 \& Westoff, 2001). The low levels of utilization are typically a function of both the limited capacity of their health system and the framework within which family planning services are delivered. Other factors affecting service provision include tenuous commodity security and suboptimal service factors (Population Reference Bureau (PRB), 2008). At the individual level also, multiple barriers to utilization have been identified, including risk perception, insufficient knowledge needed to make informed choices, opposition from male partners, and health service limitations (PRB).

Various studies conducted in Ghana show that the awareness of young people about contraceptives and where to obtain them is high. Results from the 1998 Ghana Youth Reproductive Health Survey (GYRHS) indicated that $76 \%$ of female and $88 \%$ of males all aged between 15 and 19 years were aware of at least one modern family planning method (Tweedie \& Witte (2000). Among the 12-14 year-olds, 33\% of females and 6\% of males knew of at least one modern family planning method. The condom was the most reported method known by $77 \%$ and $66 \%$ of males and females respectively. In the 1998 Ghana Demographic and Health Survey (GDHS), the proportion of both males and females aged 15-19 who knew at least one modern method was over $80 \%$. However, adolescents' knowledge of some specific methods is superficial. For example, data from the 1998 GYRHS show that while $49 \%$ of females and $25 \%$ of males all aged between 12 and 24 years knew of the pill, $21 \%$ of females and $46 \%$ of males who knew the method did not know that it has to be taken daily for it to be effective (Ghana Statistical Service [GSS], 1994 \& 1999).

In spite of the general recognition of the importance of meeting the reproductive health needs of young people and the high level of awareness among adolescents of modern methods of contraception, contraceptive use among them is generally low. Thirteen percent of all 15-19-year-old females and 35\% of married females had ever used a modern family planning method on the basis of the 1998 GDHS findings. Effective contraceptive use even 
among those at risk of pregnancy is relatively low. On the basis of the 1998 GDHS, of the females and males aged 15-19 who were sexually active, only $20 \%$ and $37 \%$ respectively, were using some form of modern contraceptive. Tweedie and Witte (2000) observed in the 1998 GYRHS that $77 \%$ of female and $85 \%$ of male sexually experienced adolescents had ever used any contraceptive method and $64 \%$ of the females and $74 \%$ of the males had ever used a modern contraceptive method. _The male condom was the most popular contraceptive method that was used by $58 \%$ of female and $71 \%$ of male respondents while the least ever used contraceptive methods were the Intra Uterine Device (IUD) and diaphragm among females (about 1\% for each method). In the study by Agyei et al.(2000), 96\% of unmarried females and $98 \%$ of unmarried males aged between 15 and19 years were aware of at least one contraceptive method (GSS, 1999). However, contraceptive use was relatively low and the most commonly used methods were the condom and the pill.

Ironically, there have been mass media education and school based programmes on sexual and reproductive health in Ghana for over two decades. The depth of students' knowledge is described as inadequate even as majority of them are afraid to get pregnant. Among adolescents aged $15-19$ years, only $28 \%$ of females and $21 \%$ of males had detailed knowledge about how to prevent pregnancies; were aware of a woman's fertile period, able to reject several popular misconceptions about pregnancy and were familiar with at least one modern method of contraception. Between the 12-14 years old group, only $12 \%$ of females and $6 \%$ of males had this level of knowledge. The report said adolescents in general expressed little confidence that they could properly use the male condom which is the most common method of protection in this age group (Awusabo-Asare et al, 2006).

It has however been observed by some researchers like Cobb (2001) that most adolescents are surprisingly misinformed about their own reproductive capabilities. Some surveys have shown that as many as two-thirds of adolescent girls believe it is not necessary for them to take precautions because they are too young to get pregnant or because they have not had sexual intercourse enough times to become pregnant. Again, it has also been observed that the use of contraceptive is not popular with teenagers because of ignorance, insufficient sex education and other reasons (Cobb, 2001).

Overall, the evidence thus far suggests that adolescents continue to be vulnerable to sexual intercourse, which results in early and unplanned pregnancies and in some cases leads to unsafe abortion. The national news paper "Daily Graphic: Tuesday, September 11, 2007" mentioned that it was on record that teenage births formed $40 \%$ of the total births in the country with the highest rate recorded in the Central Region. The high rate of teenage births is also one contributory factor to the high maternal death rate recorded in the region. Addressing these problems requires creating an atmosphere characterized by openness at the household and community levels; providing avenues in and out of school for teaching adolescents ways of protecting themselves; providing the services they need, for example to prevent pregnancy; and providing counseling concerning sexual relationships. By adopting these strategies, in an attempt to possible reach out to other adolescents population necessitated this study.

\subsection{Methodology}

A cross-sectional study was carried out between February to April 2010, in the 


\section{Al Macrothink}

Journal of Sociological Research

ISSN 1948-5468

2012, Vol. 3, No.2

Cosmopolitan city of Cape Coast of the Central Region of Ghana. Three mixed, one female and one male senior high school were conveniently identified for the study. After designing the anonymous study questionnaire, the approval of the Research and Ethics Committee of a university hospital was sought and obtained. A self-administered questionnaire was given to 350 students in the schools by proportionate sampling. Of the 350 questionnaire items given out, 300 were retrieved and used, representing a response rate of $85.7 \%$. The school authorities and students were approached, informed and their consent was duly obtained after explanation by one of the authors. Questions were asked about actual age, age at menarche, contraceptive knowledge and source of information on contraception, contraceptive usage, contraceptive type known and reasons for non-usage of contraceptives. All the data were collated and analyzed using the Statistical Package for the Social Sciences (SPSS) programme, version 15.0.

\section{RESULTS}

Table 1. Background Characteristics of Respondents

\begin{tabular}{|l|l|l|}
\hline Variable & Group & $\mathrm{N}(\%)$ \\
\hline Gender & Male & $159(53.0 \%)$ \\
\hline Age Category & Female & $141(47.0 \%)$ \\
\hline & $12-14$ & $0(0 \%)$ \\
\hline & $15-17$ & $156(52.0 \%)$ \\
\hline & $18-20$ & $144(48.0 \%)$ \\
\hline
\end{tabular}

Information regarding the background characteristics of the study participants is shown in Table 1. Males and females constituted $53.0 \%$ and $47 \%$ respectively of the study sample. Respondents' age ranged between 15 and 20 years.

Table 2. Respondents' contraceptive knowledge

\begin{tabular}{|l|l|}
\hline Characteristic & Responses (N=\%) \\
\hline Knowledge of Contraception & \\
\hline No & $56(18.7 \%)$ \\
\hline Yes & $244(81.0 \%)$ \\
\hline Source of Information on Contraceptive & \\
\hline Parents & $10(3.3 \%)$ \\
\hline Brother/Sister & $20(6.7 \%)$ \\
\hline Friend & $90(30 \%)$ \\
\hline
\end{tabular}




\begin{tabular}{|l|l|}
\hline TV/Radio & $180(60 \%)$ \\
\hline Type of Contraceptive Known & \\
\hline Condom (male/female) & $127(42.3 \%)$ \\
\hline Oral contraceptive (The Pill) & $73(24.3 \%)$ \\
\hline Injection & $10(3.3 \%)$ \\
\hline Withdrawal Method & $13(4.3 \%)$ \\
\hline Traditional Medicine & $70(23.3 \%)$ \\
\hline Others (IUD, diaphragm, sterilization etc) & $7(2.3 \%)$ \\
\hline
\end{tabular}

Of the 300 respondents, $81.0 \%$ indicated that they had knowledge about contraception and $18.7 \%$ had no idea (Table 2). When the $81.0 \%$ respondents that had knowledge of contraception were asked about their source of information on contraception, majority $(60.0 \%)$ indicated that the TV/Radio was their source of information. In addition, $30.0 \%$ had information about contraceptives from their friends, $6.7 \%$ obtained information from siblings (brother and/or sisters) and 3.3\% from their parents (Table 2).

With respect to awareness, almost all respondents could indicate at least one method of contraception (Table 2), with the most common type of contraception known as the condom $(42.3 \%)$ followed by the pill $(24.3 \%)$. Others were injections $(3.3 \%)$, "traditional" $23.3 \%$, withdrawal $(4.3 \%)$. Other methods such as sterilization (male/female), intrauterine device (IUD), and diaphragm, were least commonly known by most respondents (Table 2).

Use of Contraceptives by Respondents

Table 3. Contraceptive use among respondents

\begin{tabular}{|l|l|}
\hline Characteristics & Responses (N=\%) \\
\hline Contraceptive Use & \\
\hline Yes & $50(20.5 \%)$ \\
\hline No & $194(79.5 \%)$ \\
\hline Reason for non-usage of contraceptive & \\
\hline Has side effects & $34(13.9 \%)$ \\
\hline Not having sex & $126(51.6 \%)$ \\
\hline Not bothered though sexually active & $84(34.4 \%)$ \\
\hline Engaging in sexual activities & \\
\hline Has side effects & $21(17.8 \%)$ \\
\hline Not bothered & $97(82.2 \%)$ \\
\hline Contraceptive method used & \\
\hline Condom & $68(57.6 \%)$ \\
\hline Pill & $50(42.4 \%)$ \\
\hline Injection & $0(0 \%)$ \\
\hline Traditional medicine & $0(0 \%)$ \\
\hline Reasons for contraceptive use & \\
\hline To prevent only pregnancies & $76(64.4 \%)$ \\
\hline To prevent only STDs & $30(25.4 \%)$ \\
\hline To space child birth & $0(\%)$ \\
\hline
\end{tabular}


To prevent both pregnancies and STDs $12(10.2)$

The results indicated that only $20.5 \%$ of the study participants that had knowledge of contraception were using any of the methods as shown in Table 3 . When asked for reasons of non-usage of contraception, surprisingly, $51.0 \%$ indicated that they did not engage in sexual activities. However, among the sexually active respondents, $82.2 \%$ were not using any form of contraception because "they were not bothered"!

Furthermore, majority of the sexually active respondents (57.6\%) used condoms compared with the other contraceptive methods known. Another commonly used method was the pill $(42.4 \%)$. The common reason attributed to the use of contraceptives by most sexually active respondents was to avoid unintended pregnancies (64.4\%) and also avoid contracting STDs (25.4\%).

Table 4. Respondents Perceptions about Contraceptives

\begin{tabular}{|l|l|l|l|l|}
\hline Perception & $\begin{array}{l}\text { Agree } \\
\%\end{array}$ & $\begin{array}{l}\text { Not certain } \\
\%\end{array}$ & $\begin{array}{l}\text { Disagree } \\
\%\end{array}$ & $\begin{array}{l}\text { Total } \\
\%\end{array}$ \\
\hline $\begin{array}{l}\text { Contraceptives are for only adult married } \\
\text { persons. }\end{array}$ & 31.5 & 8 & 60.5 & 100 \\
\hline Contraceptives are so expensive to use & 13 & 25.5 & 61.5 & 100 \\
\hline $\begin{array}{l}\text { Adolescents who use contraceptives are } \\
\text { bad }\end{array}$ & 40 & 15.5 & 44.5 & 100 \\
\hline Contraceptive use leads to infertility & 18 & 46 & 36 & 100 \\
\hline $\begin{array}{l}\text { It feels bad to receive contraceptive } \\
\text { information from parents }\end{array}$ & 25 & 25 & 50 & 100 \\
\hline $\begin{array}{l}\text { The process of acquiring contraceptives is } \\
\text { often embarrassing }\end{array}$ & 43 & 34 & 23 & 100 \\
\hline
\end{tabular}

Table 4 shows the perceptions of adolescents regarding the use of contraceptives. Most (40\%) of the respondents agreed that adolescents who use contraceptives are described as bad boys and girls. Other perception statements generated varied responses. For example, $31.5 \%$ of the respondents had the perception that contraceptives were only for adult married persons, whereas $43 \%$ thought that the process of acquiring contraceptives was often embarrassing.

\subsection{Discussion}

With the current low rates of utilization of family planning methods reported in West Africa coupled with the increasing rate of HIV and other STDs infection, the concept of risk-taking and protective behavior has gained much attention in reproductive health studies. Therefore, understanding the characteristics of adolescents' populations with unmet need for family planning will be an essential part of a broad strategy to improve awareness and utilization at both community and national levels.

The study observed that there was a definite discrepancy between students' understanding of contraception and sexual behaviour. Though $18.7 \%$ of the studied group had some knowledge of contraception, as much as $48 \%$ engage in sexual activity. This rate of 
sexual activity is similar to the rates reported in other studies by the Ghana Demographic and Health Survey (GDHS [1998 \& 2003]), and further higher as reported by Agyei et al (2000), and Tweedie \& Witte (2000). A further analysis showed that, only $17.8 \%$ of the sexually active group used any form of contraception. This confirms that awareness does not translate to the use of contraception. Factors that may contribute to lack of contraceptive use or inconsistent use include issues related to adolescent development, such as reluctance to acknowledge one's sexual activity, belief that one is immune from the problems or consequences surrounding sexual intercourse or pregnancy, and denial of the possibility of pregnancy. Other important factors are lack of education and misconceptions regarding the use or appropriateness of contraception. However, an adolescent's level of knowledge about how to use contraception effectively does not necessarily correlate with consistent use. Adolescents may not use or may delay use of contraception for several reasons including lack of parental monitoring, fear that their parents will find out, ambivalence, and the perception that birth control is dangerous or causes unwanted adverse effects such as weight gain. Although it was not ascertained in our study, whether pregnancy was intended, the low rate of contraceptive usage is likely to give rise to an increased rate of unwanted pregnancies and/or abortions with attendant sequelae. If in the GDHS (1998), sexually active adolescents aged 15 to 19 years who ever used any modern contraceptive method was low, and more than half a decade down the line, Awusabo-Asare et al, (2006) also reported that a low contraceptive complaint among adolescents, then the challenge, therefore, is the need to intensify the awareness campaign for contraceptive usage among the adolescent.

Other studies ranked the family (parents, brothers and sisters) as the lowest source of information on sexuality (Odumegwe, 2002). This finding is similar to what was reported in our study. The worry is that in most typical African homes, sex and issues relating to it are taboo subjects. There is little or practically no communication on sex, even between partners. Children are compelled to learn about issues relating to their sexuality on their own. Most parents are therefore also uncomfortable talking to their children about it. They however believe someway, somehow, their wards will learn about it like they did. The events in the last two decades we believe should compel parents, guardians and teachers to re-examine their roles in reproductive health education at home and school because the influence of family and school values could help improve adolescents' sexual behaviour.

The most common method of contraception known to the respondents is the condom (42.3\%), as $57.6 \%$ of sexually active respondents were using it, an indication that some of the sexually active adolescents are having unprotected sex. In an era of HIV infection, use of the condom as protection against STIs in addition to its use as a family planning method has become important. As with other modern contraceptives, adolescents' awareness of the male condom is high, but despite the fact that it is one of the most commonly-used methods, overall levels of condom use are still low (GYRHS, 1998). The acceptability of condoms is still fraught with challenges. One reason for the low level of condom use is that young people do not feel confident in insisting on condom use in a relationship. In the 1998 GYRHS, among those who had heard of condoms, $27 \%$ of males and $30 \%$ of females said they could not insist on using a condom if their girlfriend or boyfriend did not want to use one. Moreover, about one-third of both male and female adolescents said they could not refuse to 
have sex if their girlfriend or boyfriend did not want to use a condom. The challenge being continuous advocacy on perceived self efficacy on condom consistent use and introduction of other new strategies needed to increase the acceptability and effective use of condoms, especially in high risk sexual encounters.

Again, one of the outcomes is the fact that, $82.2 \%$ of the sexually active respondents were not bothered concerning contraception. Teenage pregnancies are associated with maternal, fetal and neonatal adverse outcomes; such girls drop out of school becoming parents who are unlikely to have the economic and social means to cater for their children. This is in tandem with the findings of Okonofua (1995) where contraceptive usage was low. In this study, the finding that only $17.8 \%$ of the respondents with knowledge of contraception used any of the methods compares favourably with $13 \%$ obtained in the GYRHS (1998). This shows that after many years of family planning activity, there is still a wide gap between knowledge and usage. This is worrisome in the face of increased sexual activity amongst adolescents and the hazards of contracting sexually transmitted diseases.

Finally, the results about adolescents' perceptions confirm what other researchers have documented. Findings from Feldmen, (1997) and Havanon, Inger \& Sibon (1993) indicate that some adolescents especially girls feel that a partner's use of condom suggest that they, the girls, are not clean and that, are likened to commercial sex workers or engage in extra-relationship sexual activity. Berglund (1997) stated that another barrier to contraceptive method use stems from the alienation that many adolescents face when they visit maternal or child health clinics or pharmaceutical shops which are primary sources of contraceptive methods to buy usually condoms. To Berglund, because of overt social disapproval of premarital sexual activity and the general lack of privacy at these places, many adolescents' feel that procuring contraceptives will make them subjects of ridicule and gossip. Some adolescents are likely to face other forms of negative attitudes from health personnels, an embarrassment most adolescents' may avoid.

\subsubsection{Limitations of the Study}

1. The cross-sectional design of the study prohibits inference of causality in any way. An adolescent might report using a condom or otherwise to receive praise or self-satisfaction. Social desirability compels participants to over-report (give certain desirable responses). Also, sexual issues are very sensitive and could limit free expression on some matters.

2. The self-administered questionnaire lacks power to detect all misunderstandings despite the presence of a researcher on the field. Questionnaire administration on sensitive issues like this is prone to a number of biases that could affect the reliability and validity of a measure such as a participant's literacy level and comprehension of behavioural terminology, recall biases and self-presentation or confidentiality concerns resulting from stigmatization of a behaviour reported.

To minimise the effect of this, we ensured full confidentiality of participants, a research assistant was present in the classroom to respond to possible questions raised by participants during the data collection, and also we ensured that the questionnaire was simple and self-explanatory as possible. Finally, we established a working trust with 


\section{Macrothink}

respondents who responded to the questionnaire by including among us some of their teachers, known by them.

3. The small sample size restrains the generalization of the findings to the adolescent population within the Cape Coast Metropolis.

\section{CONCLUSION}

Despite the high rate of sexual activity in the group studied, the contraceptive usage rate is low. There is a need for aggressive advocacy about adolescent reproductive health before initiation of sexual activity and dissemination of information on family planning methods amongst the adolescents' population in Ghana. Young people are among those at a high risk of contracting HIV, yet they do not perceive themselves to be at risk and are therefore, less likely to adopt protective measures. The results indicate a low self-perceived risk of HIV and other STDs infections, early sexual debut, and negative attitudes towards condom use. Among the challenges emerging from the findings are positively promoting condoms and improving adolescents' confidence about purchasing and using them. Condom use will need to be promoted for dual protection from pregnancy and STIs, including HIV/AIDS.

\section{Acknowledgements}

The authors are grateful to all the students in the selected senior high schools who willingly agreed to participate in the study.

\section{Corresponding Author}

John Elvis Hagan (Corresponding author)

Department of Health, Physical Education and Recreation, University of Cape Coast, Ghana

Tel: +233202508073Ｅ-mail: jaguwa2006@yahoo.co.uk

\section{Authors' contributions}

JEH- conceived the idea of the study, participated in the design of the study, performed the statistical analysis, drafted the first version of the manuscript and participated in finalizing the manuscript for submission.

CB-participated in developing the manuscript, discussing the findings and in finalizing the manuscript for submission. Both authors gave suggestions, read the manuscript carefully, fully agreed on its content and approved its final version. 


\section{Macrothink}

Journal of Sociological Research

ISSN 1948-5468

2012, Vol. 3, No.2

\section{References}

Adetokunbo, T., Oluwarotimi, A., Abiola, B., Adeniyi, A., Dele, O., \& Lukeman, S. (2011). Contraceptive knowledge and usage amongst female secondary school students in Lagos, Southwest Nigeria. Journal of Public Health and Epidemiology, 3, 34-37

Agyei, W. K. A. et al. (2000). Sexual Behaviour and contraception among unmarried adolescents and young adults in grater Accra and Eastern Regions of Ghana. Journal of Biosocial Science, 32, 495-512

Awusabo-Asare, K., Abane, A. M., \& Kumi-Kyereme, K. (2006). Adolescent Sexual and Reproductive Health in Ghana: A Synthesis of Research Evidence. Occasional Report, New York: The Alan Guttmacher Institute, (No. 13).

Berglund, E. C. (1997). The background of adolescent pregnancies in Nicaragua: A qualitative approach. Social Sciences and Medicine, 44, (8), 11-12

Brooks-Gunn, J., \& Furstenberg, F. F., Jr. (1989). Adolescent sexual behavior. Am Psychol., 44, $249-257$

Cobb, J. N. (2001). Adolescent continuity, change and diversity $\left(4^{\text {th }}\right.$ ed). California; Mayfield Publishing Company.

DiClemente, R. J., Wingood, G. M., \& Crosby, R. (2001). Parental monitoring: association with adolescents' risk behaviors. Pediatrics, 107, 1363- 1368

Feldmen, D. A. (1997). Development of value utilization/norm change model. Social Sciences and Medicine, 8, 455-468

Ghana Statistical Service (GSS) (1999). 1993, 1994, 1998. Ghana Demographic and Health Survey, Accra, Ghana: Ghana Statistical Service, ibid.

Ghana Statistical Service (GSS) (2004). Noguchi Memorial Institute for Medical Research (NMIMR), ORC Macro. Ghana demographic and health survey 2003. Calverton, Maryland: GSS, NMIMR, ORC Macro.

Havanon, E., Inger, A., \& Sibbon, A. (1993). Sexual networking in Provincial Thailand: Studies in family planning. Obstetrics Gynecology, 24, (22) 11-17.

Moore, P. J., Adler, N. E., \& Kegeles, S. M. (1996). Adolescents and the contraceptive pill: the impact of beliefs on intentions and use. Obstetrics Gynecology, 88(3 suppl), 8S- 56S

Odumegwu, C. O., \& Luqman Bola-Solanke, A. A. (2002). Parental Characteristics and Adolescent Sexual Behaviour in Bida Local Government Area of Niger State, Nigeria. Afr. J. 
Reprod. Health, 6, 95-106

Okonofua, F. E. (1995). Factors associated with Youth and Adolescent Pregnancy in Rural Nigeria. Journal and Adolescent, 24, 419-438

Population Reference Bureau (2008). World Population Datasheet. Washington DC.

Reddy, D. M., Fleming, R., \& Swain, C. (2002). Effect of mandatory parental notification on adolescent girls' use of sexual health care services. JAMA, 288, $710-714$.

Shane, K., Mishra, V., Arnold, F., \& Abderrahim, N. (2007). Contraceptive trends in developing countries. DHS comparative reports. Calverton, Maryland, USA: Macro International Inc.

Tweedie, I., \& Witte, K. (2008). Ghana Youth Reproductive Health Survey Report, Accra, Ghana: Ghana Social Marketing Foundation

Westoff, Charles, F. (2002). Unmet Need at the End of the Century. DHS Comparative Reports No. 1. Calverton, Maryland: ORC Macro.

Whitaker, A. K., \& Gilliam, M. (2008). Contraceptive care for adolescents. Clinical Obstetric Gynecology, 51, 268-280

\section{Glossary}

\section{Commonly Cited Data Sources}

Ghana Demographic and Health Surveys (GDHS): The GDHS were conducted in 1988, 1993, 1998 and 2003. The GDHS are nationally representative surveys of women aged 15-49. Husbands of female respondents were included in the 1988 survey and men aged 15-59 were included in the 1993, 1998 and 2003 surveys. The surveys cover a large number of population, health and nutrition indicators. Many of the statistics cited in this report and included in the appendix tables are from analyses conducted by The Alan Guttmacher Institute using 1998 GDHS data. Statistics are also included from the GDHS country reports published by the Ghana Statistical Service.

1998 Ghana National Youth Reproductive Health Survey (GYRHS): The GYRHS was a nationally representative survey administered to 5,640 youth aged 12-24 (2,533 females and 3,107 males). This survey covered a range of sexual and reproductive health topics such as sexuality, pregnancy, abortion, STIs and HIV/AIDS, and preventive behaviors (see reference 53). Study in Ketu South, Upper Denkyira and Offinso electoral constituencies 